\title{
Learning lessons from stock transfer: the challenges in delivering second stage transfer in Glasgow
}

\author{
Kim McKee \\ University of Glasgow
}

\begin{abstract}
Summary
The 2003 housing stock transfer in Glasgow was designed to empower tenants through 'community ownership' of social housing. It involved a unique two-tier stock transfer process. From the outset, citywide housing management was devolved to a network of Local Housing Organisations. This was to be proceeded by further, smaller Second Stage Transfers in order that these organisations may own as well as manage their local housing stock. Implementing this political ambition has however been a fraught and difficult process. Indeed, more than five years on, few organisations have been able to realise their ambitions for local ownership through Second Stage Transfer. Drawing on recent empirical research, this paper seeks to outline progress to date, as well as emphasise the financial and organisational barriers that have undermined aspirations for community ownership in practice.
\end{abstract}

Keywords: community ownership, governance, housing policy, stock transfer.

\section{Introduction}

The 2003 housing stock transfer in Glasgow is the largest and arguably most complex transfer embarked upon in the UK. It was meant to be the flagship of the Scottish Executive's ${ }^{1}$ new Community Ownership Programme, but delivering local control and ownership for Glasgow's tenants has taken much longer to achieve than envisioned (Keating, 2007; McKee, 2007). Given that stock transfer has been occurring in the UK for over 20 years, it is important to interrogate why Glasgow's transfer has been so protracted and problematic (Kearns and Lawson, 2008).

Drawing on recent empirical research, the paper first discusses the origins and evolution of stock transfer policy in the UK, before detailing the particular and unique features of the 2003 Glasgow transfer. It then traces progress to date, before considering the financial and organisational barriers that have thwarted attempts to deliver community ownership on the ground. It concludes by reflecting upon what can be learned from Glasgow's experience, and the wider implications for stock transfer policy in the UK. 


\section{The Origins and Evolution of Stock Transfer Policy in the UK}

Stock transfer involves the sale of housing from the public sector (local authority or Scottish Homes) into the voluntary sector (housing association or co-operative). Originating in Scotland in the mid 1980s, it was pioneered by Glasgow District Council in an attempt to regenerate small, run-down pockets of council housing through 'community ownership' (Clapham et al, 1991). In England the origins were somewhat different and later, beginning with Chiltern District Council's transfer of their entire housing stock in 1988 (Malpass and Mullins, 2002). Uniting both approaches was the emergence of a bottom up, local initiative to transform public sector housing, which subsequently was adopted as a key central government policy (Malpass and Mullins, 2002).

Since its emergence in the 1980s the impact of stock transfer has been significant, and it has transformed the size and characteristics of both public housing and the wider social rented sector, whose growth it has facilitated (Pawson, 2006). Whilst in England over one million homes have been transferred across 130 local authorities (Pawson, 2006: 774), the proportion is even greater in Scotland where the council sector has been reduced by half compared to ten years ago (Audit Scotland, 2006: 4). Across all parts of the UK the pace and scale of transfer activity has accelerated under the New Labour government (Malpass and Mullins, 2002).

The general label of stock transfer, however, masks a range of different 'streams' or types of stock transfer that are discernable (Taylor, 2000). In England, large-scalevoluntary-transfer (LSVT) as legislated for in the 1988 Housing Act has been the predominant model, and was initially popular in rural, southern, Conservative run councils with good housing stock (Malpass and Mullins, 2002). It is only more recently that activity has been extended to Labour controlled northern and midland authorities in urban areas (Malpass and Mullins, 2002; Pawson et al, 2009).

Within Scotland, stock transfer demonstrates 'more complexity and variety' (Taylor, 1996: 4). As indicated previously, it originated in Glasgow in the mid-1980s and was linked to the efforts of Glasgow District Council to lever in both private investment and public subsidy for regeneration purposes vis a vis small, neighbourhood-level, partial transfers to local, tenant-controlled organisations (Clapham et al, 1991; Taylor, 1996; 2004). The success of this initiative saw it rolled out across Scotland as a national policy objective, and by the end of 1997 there had been 120 such transactions involving 21,000 homes (Audit Scotland, 2006: 4). It was particularly popular in Labour controlled, urban authorities in the west of Scotland (Taylor, 1996; 2004). ${ }^{2}$

Whilst the predominant model in England was LSVT this was relatively rare in Scotland until recently (Audit Scotland, 2006). Indeed, it was not until post-devolution and the election of the Scottish Executive in 1999 that stock transfer policy in Scotland really began to change scale and focus. Under the banner of 'community ownership' the Scottish Executive actively promoted whole stock transfer in Scotland (McKee, 2007). Following the initial wave of positive ballots in 2003 , success has however been more mixed, reflected in the increasing tendency of tenants to reject such proposals, as in Edinburgh and Stirling. Nonetheless, the political emphasis upon 'community ownership' is significant. It reflects an explicit desire on the behalf of government to recreate the success of the original neighbourhood transfers, and more generally, the community-based housing association (CBHA) model that emerged from this (Kintrea, 2006; McKee, 2007; 2008a). The latter is a constitutional model in which the registered social landlord is locally focused and based within the community that it serves, and where a key role is accorded to tenants in the governance of the organisation. It is a distinct feature of the housing association movement in the west of Scotland. 


\section{The Glasgow Housing Stock Transfer}

Glasgow is a city characterised by a legacy of industrial decline, unemployment, poverty and urban decay (Gibb, 2003). Once the bastion of municipal provision within the UK, council housing in Glasgow has declined from its peak of 174,000 units in 1981 to 85,000 prior to the stock transfer in 2003 (GHA, 2003: 17). Despite a long history as a "change leader" in remaking social housing both within and beyond the council sector (Maclennan and Gibb, 1988: 5), Glasgow remains a city plagued by both poor housing and neighbourhood decline (Keating, 2007). Given the sheer scale of the city's housing problems, and the promise of the UK Treasury to write-off Glasgow's housing debt if whole stock transfer went ahead, it is not unsurprising that transfer was presented by both the City Council and the Scottish Executive as the best, and indeed the only, solution (GCC, 2001; Gibb, 2003).

In April 2002, 58 percent of those tenants who voted in the ballot voted 'yes' for transfer (Gibb, 2003: 90). Consequently, the entire housing stock of Glasgow City Council was transferred in March 2003 to the newly created Glasgow Housing Association (GHA) - now Britain's largest social landlord. The GHA made significant promises to tenants around the 'four R's' of repairs, rents, rights and regeneration (GCC, 2001; 2002). A focus on warm, dry and secure homes was accorded a matter of priority. However, it was not just the physical improvement of the properties that was at the heart of the tenant promises. More fundamental perhaps was the explicit commitment to local control through the creation of a decentralised governance structure (GCC, 2001; 2002; GHA, 2003). Whilst GHA is the landlord, and owns the properties, day-to-day management of the housing has been devolved to a citywide network of over 60 Local Housing Organisations (LHOs). These are either new or existing registered social landlords providing services to GHA under terms outlined in a legal contract. Both small-scale and community-controlled these LHOs are governed locally by a management committee comprising a majority of tenants (McKee, 2007).

The 2003 stock transfer was therefore not an end in itself. Rather the devolved organisational model it established in partnership with the LHO network was envisaged as merely the 'first step' on the pathway to full community ownership (GHA, 2005: 1; see also McKee, 2007). A goal which is to be realised by enabling the LHOs to own as well as manage the local housing stock through further, smaller secondary stock transfers in a unique process called Second Stage Transfer (SST). Here explicit links were made by the architects of the Glasgow transfer between a 'successful' model of social housing and the community-based housing movement, with stock transfer being the tool to deliver this political ambition.

\section{Methodology}

The research draws on ethnographic case study research conducted in Glasgow between August 2005 and April 2006. It involved a variety of qualitative methods, not all of which are featured here (for full discussion see McKee, 2007). This paper draws primarily on empirical data from 54 semi-structured interviews with: LHO housing staff, both front-line and management level; LHO committee members who are residents of the local area; and members of Scotland's wider housing and policy community (local councillors, the GHA, the Scottish Executive). It was complemented by the analysis of key policy documents from the local, citywide and national (Scotland) levels, which range from the pre-transfer period to the current day. For confidentiality purposes the names of all individuals have been removed. Where direct quotes are used the interviewer's comments are shown in italics. 


\section{Delivering Community Ownership in Glasgow: progress so far}

SST was both an explicit and central feature of the transfer framework in Glasgow, with a specific commitment made to ballot tenants on further, secondary transfers within 10 years of the initial transfer from the City Council (GHPS, 2000). As the current owner of the housing, the GHA is charged with the task of delivering community ownership for Glasgow's tenants. SST is a key priority for the organisation, as outlined in both its pretransfer and subsequent business plans:

Tenants' needs come first. We are committed to working with tenants to improve the quality of their homes and the services they receive. We will encourage and support tenants to participate in the management of their homes, and to take over ownership via secondary transfer if that is what they wish (GHA, 2003: 11).

In practical terms SST involves the sale of the local housing stock that is presently owned by the GHA to the LHOs, in order the latter might own as well as manage it. This requires negotiations between the buyer (the LHOs) and the seller (the GHA) in terms of reaching a mutually agreeable price for transferring ownership of the housing. Being both unique and particular to the Glasgow transfer context, SST is however an untested and untried transfer model. There is no precedent to provide guidance on how to resolve the seemingly intractable practical barriers that have subsequently emerged:

SST is simply the most difficult process ... it's mind bendingly complex and there's no foundation in the economic sense within the business plan, or indeed within any of the other structures that hold us up ... so we had this absolute sacred cow and no way of feeding it (Senior Representative 1, GHA).

Well the problems they [the GHA] are hitting now ... They are inherent to the whole process. Nobody had ever done it [SST] before (Independent Stock Transfer Consultant).

As Figure 1 emphasises, the realisation of SST is not a simple process. Rather there are multiple steps prospective purchasers must complete before they can proceed to local ownership of the housing. Importantly, at each of the key stages identified the GHA must respond to an LHO's submission and the GHA Board must agree to further progression. This affords the GHA prime control over the negotiation process, for ultimately the organisation need not consent to transfer the ownership of its housing on terms which it deems unfavourable. The ability of LHOs to realise their ambitions for SST is therefore heavily dependent on decisions outwith their control and taken elsewhere (by the GHA board). Yet tenants are also accorded power in this process. Unless they lend majority support to SST at local ballots, further transfers of ownership cannot proceed (GCC, 2001; McKee, 2008b; 2009). 
Figure 1: Steps on the Pathway to Community Ownership

Stage 1 - stock condition survey and outline submission for SST by potential purchaser to GHA

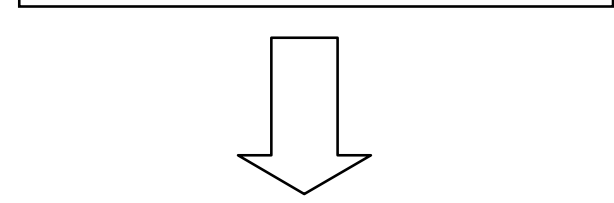

Stage 2 - agreement between buyer/seller on stock valuation and the necessary private funding arrangements in place

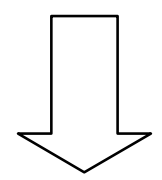

Stage 3 - detailed business proposal: what the purchaser will deliver for its tenants locally and its future plans. Must also deliver original transfer commitments to tenants

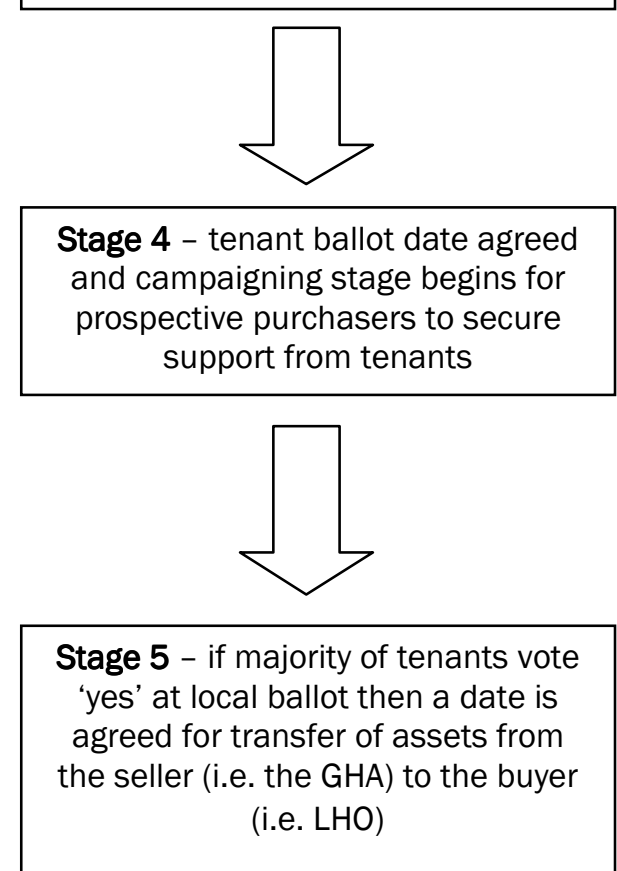




\section{p. 21. Learning lessons from stock transfer: the challenges in delivering second stage transfer in Glasgow}

In order to take this process forward the GHA have introduced a range of different programmes and initiatives, as outlined in Table 1. This culminated in the first wave of tenant ballots being held in November 2008, all of which returned overwhelmingly positive results in favour of SST. Over 2,000 homes will now be transferred from the GHA to the five LHOs in question. As the GHA website (2008a) reported, the ballots, which attracted turnouts of between 50 and 70 percent, received significant levels of support, with yes votes in the region of 83 to 95 percent returned. Although this only represents a small percentage of GHA's stock, it is a positive step forward after years of difficult negotiations and financial wrangling.

Table 1: Second Stage Transfer Timeline

\begin{tabular}{ll}
\hline YEAR & ACTIVITY \\
\hline 2003 & $\begin{array}{l}\text { The Prototype SST programme was established involving 17 LHOs (16,000 } \\
\text { homes in total). It was designed to test the feasibility of SST and different } \\
\text { possible configurations. }\end{array}$ \\
\hline 2004 & $\begin{array}{l}\text { The Pilot SST programme was formed, replacing the previous Prototype } \\
\text { programme. The number of LHOs involved was reduced to seven (7,000 homes } \\
\text { in total), and the emphasis shifted to delivering SST under different conditions. } \\
\text { As such, the programme included a range of different LHO types with varied } \\
\text { stock profiles. }\end{array}$ \\
\hline 2005 & $\begin{array}{l}\text { The GHA announced a faster than initially planned disaggregation process, and } \\
\text { invited all LHOs to submit bids for SST by the end of 2005. This was managed } \\
\text { through the Community Ownership Intentions Process, which was designed to } \\
\text { ensure only viable LHOs are able to proceed with SST. During this period, two of } \\
\text { the seven LHOs involved in the Pilot Programme dropped out. }\end{array}$ \\
\hline 2006 & $\begin{array}{l}\text { The Joint Team Report was published. It involved a range of stakeholders and } \\
\text { concluded that SST could not be delivered for every LHO within the existing } \\
\text { financial envelope. }\end{array}$ \\
\hline $\begin{array}{l}\text { Decisions were made on the submitted business cases by the GHA. At the end } \\
\text { of 2007, 16 organisations had their proposals endorsed, 17 were subject to } \\
\text { further review, five were rejected and } 25 \text { opted not to submit and instead } \\
\text { remain with the GHA. This brought the previous Pilot Programme to an end. } \\
\text { Interestingly, two of the pilot organisations had their bids rejected. }\end{array}$ \\
$\begin{array}{l}\text { At the end of 2008 the first five SST tenant ballots were held. All of which } \\
\text { received overwhelming tenant support and will now result in SST. }\end{array}$ \\
$\begin{array}{l}\text { 31 organisations managing over 20,000 homes continue to progress through } \\
\text { the SST process, with the aim of balloting tenants and concluding the } \\
\text { transactions by 2011. The remainder of the LHOs not proceeding to SST will } \\
\text { remain within a restructured GHA. }\end{array}$ \\
\hline 2007 Source: GHA website (www.gha.org.uk)
\end{tabular}

\section{It's all about the Money}

At the close of fieldwork in 2006, both the GHA and potential purchasers (the LHOs) were locked in a stalemate situation because of their inability to agree a valuation price and secure the required funding for SST. The distance between the two parties on this key issue contributed to what some LHO actors described as a 'groundhog day' scenario in which the same issues were being revisited again and again in search of a mutually agreeable outcome. As the next section will explore, this impasse regarding the price and ultimate fundability of the project has major implications for the future governance and structure of both the LHO network and the GHA. Until all the steps have successfully been negotiated, community ownership via SST cannot be realised. 
Unlike traditional stock transfers, SST involves a commercial business-to-business transfer as opposed to the disposal of public sector assets. As such there is no additional public expenditure available to underwrite the purchase price, fund transaction costs, or to facilitate an extensive package of promises to entice tenants to vote for it. All the buyer and seller have to work with is the GHA business plan that was the basis of the original transfer from the City Council in 2003.

This is reflected in the valuation methodology proposed by the GHA (for detailed discussion see Pawson, et al 2009). Particularly in relation to the discount rate, which brings future rents and costs as outlined in the purchaser's business plan back to a present day sum, and thereby enables a selling price to be calculated. Traditional stock transfers in Scotland (e.g. Scottish Homes) employed a discount rate of around six to seven percent in order to favour the purchaser and facilitate transfer, which was mutually beneficial for all parties involved. However, as a private seller the GHA can set its own discount rate, which it has done so at a level of around three to four percent. This is considerably lower than enjoyed in other transfer streams and has the effect of pushing the sale price up.

The crux of this debate is therefore one of financial resources and the inability of the LHOs to purchase the GHA stock in the traditional way. This manifested itself in an "expectation gap" between the price of SST as set by the GHA, and what potential purchasers were willing and able to pay:

Breaking up the resource base is really obviously where the rub comes, I mean we do represent a set of resources and they [the CBHA LHOs] want access in a fairly traditional way and we're unable to discharge it in a traditional way (Senior Representative 1, GHA).

There's this term at the moment in politics, called dog whistling, which is common in America and is where you say something but you mean something entirely different ... So in this debate whatever people say they are talking about, it's money ... Think of dog whistling because underneath all of this it's all about who gets what of the cake (Senior Representative 2, GHA).

This debate has become crystallised around the pivotal concept of 'financial neutrality' - an explicit commitment that SST should not compromise the GHA's commitment to its lenders and the promises that it made to tenants at the initial transfer. A somewhat vague and contested concept, financial neutrality rests on the idea that tenants remaining with the GHA (that is, not transferring to SST immediately) should be no better or worse off because of it. Whilst this position was explicit in both the initial transfer framework and the GHA's pre-transfer business plan, it is one that has angered and frustrated potential purchasers.

In particular, LHO actors have emphasised that without some kind of government intervention they will be unable to secure the necessary private funding to underwrite their aspirations for ownership of the local housing stock. This is because private lenders will not lend more than independent valuers have valued the stock, or if they do, it will be at rates so high that a significant debt burden will be incurred by the purchasing LHO. However, the GHA has retorted that it cannot give the LHOs what they seek, for there is no scope within their business plan to fund individual stock transfers along traditional lines; a position subsequently echoed by the Scottish Executive and the housing regulator (Joint Team, 2006; CS, 2007; SHR, 2008). Key stakeholders have also criticised the LHOs (particularly those associated with existing CBHAs) for seeking to 'build their empires' through growing their business, whilst refusing to bring their own resources to the negotiating table (see also McKee, 2006; 2007). Indeed, a 
representative from the City Council stated the idea of 'financial neutrality' was enshrined in the transfer agreement precisely to prevent existing CBHAs "assetstripping" the GHA's stock and leaving them with the most problematic housing.

Given the scale and uniqueness of the Glasgow transfer, the present financial hurdles are perhaps not that surprising. Yet what is remarkable is the failure to anticipate and plan for such challenges at the outset of the process, especially as such problems were anticipated by the Council (see also Pawson et al, 2009):

While it appeared to be theoretically possible to achieve SST, neither the financial nor the operational detail of how to achieve SST had been worked out at the time of transfer. At that time, the network of LHOs had yet to be formed and there was no certainty about how many would make suitable landlords. Not all the information needed to assess the impact and cost of SST was available and everyone was keen to start investing and making changes for tenants as quickly as possible ... This means GHA needed to start from scratch to define what conditions (for example, financial neutrality) meant in practice and to develop a model for SST (CS, 2007: 42).

One of the reasons why there hasn't been any Second Stage Transfer activity is because financially it doesn't work ... That's why GHA have hit the buffers. Now we [the City Council] demonstrated that at the time. So it's not maybe an unexpected problem? Well it's not unexpected to us and it shouldn't be unexpected to them either (Senior Representative, Development and Regeneration Services, Glasgow City Council).

The failure to deliver SST not only reflects a 'fatal weakness in the transfer model' (Pawson et al, 2009: 21), but also is indicative of the rather simplistic policy analysis underpinning the whole transfer framework. It assumed that all that had to be done to solve the city's housing problems was to recreate the success of previous community ownership stock transfers and the model of housing governance that emerged from this: the CBHA model. Yet this ignores the uniqueness of the Glasgow transfer framework, both in terms of the scale of the housing and the two-stage transfer of ownership (see also, CS, 2007; Kearns and Lawson, 2008).

\section{Organisational Tensions and the Future of the LHO Network}

GHA's organisational structure is both unusual and untypical. Paradoxically, it has to deliver a citywide housing service, whilst simultaneously endeavouring to break-up the organisation through SST. This not only represents a key source of inter-organisational tension, but also has a bearing on the price of SST, as well as the practicalities of being able to deliver it.

The 2005 Community Ownership Intentions Process indicated that virtually all LHOs wanted to transfer away from the GHA on an individual basis as sole purchasers of the stock they manage. Given the large number and small size of the individual LHOs, the GHA stressed they may need to amalgamate into larger acquiring associations if SST is ever to be financially viable. ${ }^{3}$ Therefore despite strong aspirations for enhanced local control within the LHO network, the clear message emanating from the GHA was the need for these local organisations to 'merge' and share services if community ownership is to be realised. Amalgamation not only permits the disaggregation of centrally based staff and overheads, but also progresses the break-up of what was intended to be a transitional organisation. 
Since the end of 2006, and as a pre-cursor to SST, the LHOs have had to join together in area based shared service hubs. This allows staff presently based at GHA central offices to move out and deliver key services, such as investment, finance, human resources and project management in a more decentralised fashion (GHA 2006). More recently, it has also been proposed that LHO committees will link with new regional housing committees (GHA, 2008b). Both of these measures serve to create a further tier of governance between 'the centre' (the GHA) and 'the local' (the LHOs). Whilst it may offer a middle ground between the current primary-secondary model and 'full' community ownership, the impact of such amalgamations on the autonomy of local committees is a real point of contention. Although some LHOs recognise the benefits of shared services in terms of the relocation of specialist support staff to a more localised level, or at the very least reluctantly accept it as a compromise they must make, a minority of LHOs were strongly critical of, and actively resisted, these manoeuvres. They argued that, not only did it introduce another tier of bureaucracy that is removed from the direct control of local tenants, but that it was in fundamental opposition to the aspirations of the transfer framework, and a potentially backwards step to the centralisation and bureaucracy of the Council days:

... Shared services is the back door to saying 'come on we'll just all get together' ... It is worrying, because that is not community ownership and it is not what we voted for either, and my big worry is that we're gonna end up council mark II: 25,000 houses in each area or something like that (LHO Committee Member, Office Bearer).

The amalgamation and grouping of individual LHOs was not restricted to plans for delivering shared services, but was also a recurring theme in discussions about the viability of future SSTs. From the GHA's perspective a rationalisation of the LHO network in order to create fewer, larger and more sustainable organisations enables some of the inherent complexities and financial barriers bedevilling the funding of SST to be overcome. This is because the cost of SST is less if there are fewer purchasers involved, thus allowing efficiencies and resources to be maximised. Nonetheless it was an issue the LHOs were unwilling to compromise on, especially given their explicit desire to become independent landlords in their own right. They were also unconvinced that forming new group-structures via shared services would impact on the price of SST. Indeed, the shift towards rationalisation of the LHO network fuelled demands from the LHOs and their supporters that there should not be one uniform model of SST for all, and that the GHA needed to be more flexible and respond to the differing needs and aspirations within the LHO network:

Some LHOs may be quite happy with their degree of influence and operating within that primary/secondary model, with the GHA going on and being a body that provides services ... but that shouldn't be mutually exclusive from doing straight transfers to organisations that just want to behave independently (Former Civil Servant, Scottish Homes).

[SST] is a bit like believing in God ... so you've kind of got 'yeh we all believe in second stage transfer' but there's a million different ways of getting there (Senior Representative, Housing and Tenant Support Organisation).

These arguments seem to have triumphed, for all the LHOs that have progressed through the gateway process to ballot their tenants on SST have done so as individual purchasers. Here the existing CBHAs have been the vanguard of community ownership, which is perhaps to be expected given their previous experience of stock transfer, and ability to bring their own resources to the process. The future of the 
Forum LHOs, which were newly created at the point of transfer, is however more uncertain. Indeed, the GHA has now explicitly stated that there will not be SST for all, with the majority of Forum LHOs expected to remain within a restructured GHA:

We have gone through many iterations of ways in which SST could be progressed within the legal and financial parameters set for us. The reality is that without substantial additional public subsidy, it is not possible to transfer all our houses to local organisations (GHA, 2008b: 7).

The implication of this statement is significant. No longer is the GHA a transitional organisation, rather it is one with a long-term future and which will remain Glasgow's largest social landlord for some time to come. The inability to deliver community ownership is not only disappointing given the time and effort invested, but has been described as a fundamental "failure" of the transfer framework by many of the key actors engaged in the process.

\section{Conclusion}

Despite the potential of the Glasgow transfer framework to deliver greater local control, community ownership remains a continually elusive dream for the majority of LHOs. The range of practical barriers that have served to frustrate ambitions for further secondary transfers, suggest a lack of foresight, if not a degree of simplistic policy analysis, on behalf of the Scottish Executive: the main driving force behind the Glasgow transfer framework. Pre-transfer, not only was a lack of attention accorded to vital funding and organisational issues pertaining to the transfer of the housing stock from the GHA to the LHOs, but even now key actors continue to squabble over how, and at what cost, the housing is to be broken up and shared between the LHOs. The importance of tenants in all of this seems to have been forgotten, with attention instead centred on financial resources, business plans and cash flows.

This raises important questions about whether the Glasgow transfer framework can indeed deliver what it promised, and if not, how a revised governance model for the LHO network can be reconciled with ambitions for community ownership of the local housing stock. Given it is now clear that SST will not be realised in the form that was originally envisaged (that is, individual transfers from the GHA to each LHO), much compromise and negotiation lies ahead if bottom up aspirations for local control are to be achieved within the financial resources available. Ultimately, "community ownership' is a policy that comes with a price tag attached and if additional resources are not going to be forthcoming then ambitions may have to be lowered accordingly.

Glasgow's experience offers crucial lessons for other stock transfer landlords, not least the importance of having a sound business plan upon which to build a transfer framework. Beyond financial issues, the Glasgow situation also underlines the need for key stakeholders to work together and pull in the same direction. Many of the practical barriers inherent to SST have been further exacerbated by a set of irreconcilable tensions and conflicts within the GHA's internal governance structure and its wider operating environment. Finally, the protracted and difficult process of realising community ownership emphasises that this two-stage stock transfer model cannot succeed without significant forward planning and public subsidy. It is not a cheap or easy model to deliver, and requires significant commitment from all parties involved. This includes tenants. Although the first SST ballots were overwhelmingly positive in favour of transfer, there is no guarantee this will be echoed citywide. Key stakeholders therefore need to avoid assuming tenant support, or taking it for granted. Indeed, 
more research is needed into an 'ordinary' tenants perspective in order to understand their views and experiences of the stock transfer process to date.

\section{Notes}

${ }^{1}$ Scottish Executive refers to the first administration of the Scottish Parliament, which was in power during the period of this research. This was a coalition government between Labour and the Liberal-Democrats. In 2007 it was replaced by the SNP minority government and rebranded the Scottish Government.

2 The New Towns/Scottish Homes transfer also represent a distinct dimension of stock transfer policy in Scotland (Goodlad and Scott, 1996).

3 The LHOs number approximately 60 across the city, and range from 50 to 4000 properties in size.

* Correspondence Address: Dr Kim McKee, Department of Geographical and Earth Sciences, University of Glasgow, East Quadrangle, Glasgow, G12 8QQ. Email: kim.mckee@ges.gla.ac.uk. Tel: 01413302326.

\section{References}

Audit Scotland (2006) Council Housing Transfers. Edinburgh: Audit Scotland.

Clapham, D., Kintrea, K. and Whitefield, L. (1991) Community Ownership in Glasgow: an evaluation. Edinburgh: the Scottish Office.

CS (2007) Glasgow Housing Association Inspection Report. Edinburgh: Communities Scotland.

GCC (2001) Proposal to Transfer the City Council's Housing to Glasgow Housing Association: stage 1 statutory notice. Glasgow: Glasgow City Council.

GCC (2002) Glasgow Housing Transfer: stage 2 statutory notice. Glasgow: Glasgow City Council.

GHA (2003) GHA's Business Plan at the Point of Transfer. Glasgow: Glasgow Housing Association.

GHA (2005) Local Housing Organisations. Retrieved 25/5/2005: http://www.gha.org.uk/content/default.asp?page $=$ s13

GHA (2006) Transforming the Network: creating shared services. Glasgow: the Glasgow Housing Association.

GHA (2008a) Tenants Cast Their Vote in Second Stage Transfer. Retrieved 20/2/09: http://www.gha.org.uk/content/default.asp?page $=$ s25 $1 \&$ newsid $=2412 \&$ back $=$ home Corporate $\% 20$ Info

GHA (2008b) Above and Beyond: Shaping a New Vision for GHA: Business Plan for 2009/10: Draft for Consultation. Glasgow: Glasgow Housing Association.

GHPS [Glasgow Housing Partnership Steering Group] (2000) Better Homes and Stronger Communities. Retrieved 25/5/2005: http://www.gha.org.uk/content/mediaassets/doc/framework\%20agreement.pdf

Gibb, K. (2003) Transferring Glasgow's Council Housing: financial, urban and housing policy implications. European Journal of Housing Policy, 3, 1, 89-114.

Goodlad, R. and Scott, S. (1996) Housing and the Scottish New Towns: a case study of policy termination and quasi-markets. Urban Studies, 33, 2, 317-355.

Joint Team (2006) Second Stage Transfers: Joint Team Report to the Minister for Communities and Glasgow Housing Association Board. Retrieved 16/2/09: 
p. 27. Learning lessons from stock transfer: the challenges in delivering second stage transfer in Glasgow

http://www.communitiesscotland.gov.uk/stellent/groups/public/documents/web pages/cs 016875.pdf

Kearns, A. and Lawson, L. (2008) Housing Stock Transfer in Glasgow - the First Five Years: a study of policy implementation. Housing Studies, 23, 6, 857-878.

Keating, D. (2007) The Transfer of Council Housing to Housing Associations in the United Kingdom: A Glasgow, Scotland Case Study. Paper presented at the European Urban Regeneration Association conference, University of Glasgow 2007.

Kintrea, K. (2006) Having it All? Housing Reform under Devolution. Housing Studies, 21, 2, 187-207.

Maclennan, D. and Gibb, A. (1988) Glasgow: no mean city to miles better. Glasgow: Centre for Housing Research, University of Glasgow.

Malpass, P. and Mullins, D. (2002) Local Authority Housing Stock Transfer in the UK: from local initiative to national policy. Housing Studies, 17, 4, 673-686.

McKee, K. (2006) Community ownership: the Glasgow housing stock transfer. Paper presented at the European Urban Regeneration Association conference, University of Warsaw, May 2006.

McKee, K. (2007) Community Ownership in Glasgow: the devolution of ownership and control, or a centralizing process? European Journal of Housing Policy, 7, 3, 319336.

McKee, K. (2008a) Transforming Scotland's Public Sector Housing through Community Ownership: the reterritorialisation of housing governance? Space and Polity, 12, 2, 183-196.

McKee, K. (2008b) Empowering Glasgow's Tenants through Community Ownership: summary of research findings, December 2008. Glasgow: University of Glasgow.

McKee, K. (2009) The 'Responsible' Tenant and the Problem of Apathy. Social Policy and Society, 8, 1, 25-36.

Pawson, H. (2006) Restructuring England's Social Housing Sector Since 1989: undermining or underpinning the fundamentals of public housing? Housing Studies, 21, 5, 767-783.

Pawson, H., Davidson, E., Morgan, J., Smith, R. and Edwards, R. (2009) The Impacts of Housing Stock Transfers in Urban Britain. JRF and ClH: York and Coventry.

SHR (2008) Glasgow Housing Association: Second Stage Transfer: valuation study by Mazars LLP: an assessment by the Scottish Housing Regulator. Edinburgh: Scottish Housing Regulator.

Taylor, M. (1996) Transferring Housing Stock: issues, purposes and prospects, Occasional Papers on Housing 10. Stirling: University of Stirling, Housing Policy and Practice Unit.

Taylor, M. (2000) Stock Transfer Past and Present: a summary of research evidence, Scottish Homes Research Review Number 6. Edinburgh: Scottish Homes.

Taylor, M. (2004) Policy Emergence: learning lessons from stock transfer, In: D. Sim (ed.) Housing and Public Policy in Post-Devolution Scotland. Coventry: $\mathrm{ClH}$. 